\title{
The effect of feature-target intervals in
} conditional discriminations on acquisition and expression of conditioned nictitating membrane and heart rate responses in the rabbit

\author{
E. JAMES KEHOE, NERIDA PALMER, GABRIELLE WEIDEMANN, and MICHAELA MACRAE \\ University of New South Wales, Sydney, Australia
}

\begin{abstract}
Nictitating membrane (NM) and heart rate (HR) responses were investigated in a conditional discrimination $(\mathrm{A} \rightarrow \mathrm{X}+\mathrm{vs.} \mathrm{B} \rightarrow \mathrm{X}-$ ), using feature-target intervals of $0,5,15$, and $45 \mathrm{sec}$. Conditional control of NM responses, but not of HR responses, was acquired to the 400-msec X stimulus in all the groups tested. However, differential conditioning of both the NM and the HR responses to A versus B feature cues appeared for the three shorter intervals. Following acquisition, all the rabbits were tested with the four different feature-target intervals. All the groups showed a gradient of NM responding to X, in which the highest level of responding occurred at or near the interval used in training. The results are discussed with respect to the relationship of simple conditioning of the feature cues to their control over responding during presentation of the target stimulus, the putative role of $\mathrm{HR}$ as an index of preparatory processes during presentation of feature cues, and mechanisms of temporal specificity in conditional discriminations.
\end{abstract}

The present research addressed two issues concerning conditional discriminations in which a target stimulus $(\mathrm{X})$ was reinforced in the presence of one feature cue $(A \rightarrow X+)$ but was presented without reinforcement in the presence of another feature cue $(B \rightarrow X-)$. The target stimulus $(X)$ was brief $(400 \mathrm{msec})$, whereas the feature cues (A and $B)$ were much longer $(65 \mathrm{sec})$. The first issue concerned the time constraints on the feature cues in their relationships to the target stimulus and the reinforcer. The second issue concerned the significance of conditioned responding during presentation of the feature cues.

With regard to the first issue, there is some uncertainty as to how sensitive conditional control over the rabbit's eyelid response is to the interval between the onset of a feature cue and the onset of the target stimulus. When the feature cues and the target stimulus are both brief $(\leq 800 \mathrm{msec})$, differential responding to the $\mathrm{X}$ stimulus in $\mathrm{A} \rightarrow \mathrm{X}+$ versus $B \rightarrow X-$ has been found to diminish over featuretarget intervals ranging from $1,100 \mathrm{msec}$ up to $12,200 \mathrm{msec}$ (Kehoe, Marshall-Goodell, \& Gormezano, 1987). Moreover, using similar brief stimuli $(800 \mathrm{msec})$, Weidemann, Georgilas, and Kehoe (1999) found that expression of a conditional discrimination was sensitive to test manipulations of the feature-target interval. Specifically, they conducted training using feature-target intervals of 0,800 ,

Preparation of this manuscript was supported by Australian Research Council Grant A79800067. Correspondence concerning this article should be addressed to E. J. Kehoe, School of Psychology, University of New South Wales, Sydney, NSW 2052, Australia (e-mail: j.kehoe@, unsw.edu.au).
2,400 , and 5,600 msec. Across this range, they were able to establish similar levels of discriminative responding to the target stimulus. However, altering the feature-target interval in testing yielded a gradient of responding centered on the interval used in training. The appearance of such gradients has been construed as indicating temporal specificity in conditional control (Holland, Hamlin, \& Parsons, 1997).

The durations of conditional cues lie along a continuum ranging from relatively phasic stimuli, such as those described above, to increasingly tonic stimuli. In some cases, the conditional cues fill the entire feature-target interval and continue throughout the presentation of the X stimulus (see, e.g., Brandon \& Wagner, 1991; Kimmel $\&$ Ray, 1978). In other cases, the feature cues extend past the presentation of the $\mathrm{X}$ stimulus and the unconditioned stimulus (US) (Macrae \& Kehoe, 1995; Weidemann \& Kehoe, 1997). In still other cases, a conditional cue can arise from distinctive, contextual features of a conditioning chamber present for an entire training session (Asratyan, 1965; Bouton, 1991; Grahame, Barnet, \& Miller, 1992; Grahame, Hallam, Geier, \& Miller, 1990). For such long conditional cues, it is less clear whether a conditional discrimination is sensitive to the feature-target interval. For example, Weidemann and Kehoe found that, when the feature cues had a fixed duration of $41 \mathrm{sec}$, acquisition of the conditional discrimination was similar whether the feature-target interval was 0 or $20 \mathrm{sec}$. In similar experiments, Macrae and Kehoe (1995) observed acquisition of a strong conditional discrimination when the featuretarget interval was $61 \mathrm{sec}$. To date, there has been no systematic delineation of the effects of feature-target inter- 
vals when using long feature cues on the acquisition of conditional control in the rabbit eyelid response.

At present, it is unknown whether the rabbit eyelid response shows temporal specificity in conditional discriminations that use long feature cues. However, in recent studies of appetitive conditioning in rats, there is evidence of temporal specificity when long feature-target intervals are used. Most notably, Holland et al. (1997) trained rats in a serial feature positive discrimination $\left(\mathrm{A} \rightarrow \mathrm{X}^{+}, \mathrm{X}^{-}\right)$. The animals were then tested with a range of feature-target $(\mathrm{A} \rightarrow \mathrm{X})$ intervals. Test performance was better when the target stimulus $(X)$ was presented at its customary time after the feature cue (A) than when the target was presented at an earlier or a later time. For example, one group of animals was trained with a 5 -sec feature-target interval, and the test intervals ranged from 0 to $65 \mathrm{sec}$. The animals showed the greatest discrimination with a 5-sec test interval. When tested with either simultaneous stimuli $(0 \mathrm{sec})$ or the next longest serial interval $(10 \mathrm{sec})$, discriminative responding dropped away equally. Evidence of temporal specificity has also been obtained in aversive conditioning of rats using featurenegative training with feature cues that were $10 \mathrm{sec}$ in duration (Barnet \& Miller, 1996; Denniston, Cole, \& Miller, 1998).

With regard to the second issue, the profound influence of the feature cues over responding to the target stimulus seems unrelated to whether or not the animals show the same response to the feature cues. If the feature cue is relatively brief and its onset relatively close to the target stimulus, eyelid conditioned responses (CRs) will appear to the positive feature cue, largely as a result of secondorder conditioning (Kehoe et al., 1987). If the feature cue is long and its onset more distant from the target stimulus, eyelid CRs are not acquired (Macrae \& Kehoe, 1995; Weidemann \& Kehoe, 1997). It has been this latter type of result that has helped spawn a variety of theories postulating a special type of associative function in which a feature cue does not directly elicit the $C R$ but modulates the expression of the CR to the target stimulus (e.g., Holland, 1983, 1992; Rescorla, 1985; Schmajuk, Lamoureux, \& Holland, 1998).

\section{EXPERIMENT 1}

In Experiment 1, we explored more fully the effects of the feature-target interval for long feature cues $(65 \mathrm{sec})$ on conditional responding to the target stimulus and, also, on responding during the feature cues themselves. Specifically, we conducted training with feature--target intervals of $0,5,15$, and $45 \mathrm{sec}$. First, we wished to compare directly the acquisition of conditional responding over a wide range of feature-target intervals. Second, we wished to determine whether gradients indicative of temporal specificity in conditional responding would appear when the feature-target intervals were varied in testing.

Third, we examined responding to the feature cues in two ways: by examining eyelid CRs themselves and by examining heart rate (HR). Empirically, HR conditioning takes place over much longer conditioned stimulus (CS)US intervals than does eyelid conditioning. Acquisition of an HR CR can be obtained at CS-US intervals stretching up to $21,000 \mathrm{msec}$ (Schneiderman, 1972). Hence, at the longer feature-target intervals, HR could be used to index simple differential conditioning during the feature cues. Theoretically, HR has often been used as an index of underlying emotional, attentional, preparatory, and/or orienting activity, which might be related to the mechanisms of conditional control exercised by feature cues (for alternative views on the theoretical significance of HR conditioning, see Black \& de Toledo, 1972; Lennartz \& Weinberger, 1994; Obrist, Sutterer, \& Howard, 1972; Rescorla \& Solomon, 1967; Thompson et al. 1987).

\section{Method}

\section{Subjects}

The subjects were 32 female, albino rabbits (Oryctolagus cuniculus). On arrival from the university's breeding unit, they were 70-80 days old and weighed approximately $1.5 \mathrm{~kg}$. All the rabbits were individually housed and had free access to food and water.

\section{Apparatus}

The apparatus and recording procedures for the nictitating membrane (NM) response were modeled on those described by Gormezano (1966). Each subject was restrained in a Perspex box and trained individually in one of eight ventilated conditioning chambers. In each chamber, a speaker was mounted approximately $8 \mathrm{~cm}$ anterior to and $16 \mathrm{~cm}$ above the subject's head. The speaker delivered two auditory feature cues, which were a 1000-Hz, 94-dB (SPL) tone and a 94-dB (SPL) white noise. A constant background noise $(81 \mathrm{~dB}, \mathrm{SPL})$ was provided by a ventilating fan positioned at the rear of the conditioning chamber. An $8-W$ neon light tube was mounted $4 \mathrm{~cm}$ above the speaker. The light provided the ambient light source and was flashed at $20 \mathrm{~Hz}$ to provide the target stimulus. The US was a $50-\mathrm{msec}, 3-\mathrm{mA}, 50-\mathrm{Hz}$ ac current delivered via stainless steel Autoclip wound clips positioned $10 \mathrm{~mm}$ apart, $15 \mathrm{~mm}$ posterior to the lateral canthus of the rabbit's right eye. The stimulus events and response recording were controlled by an Apple II computer equipped with interfaces and software developed by Scandrett and Gormezano (1980).

To transduce movements of the rabbit's NM, a small hook was attached to a silk loop sutured into the NM of the rabbit's right eye. The hook was connected to one end of an L-shaped crank that operated a photoelectric transducer (Gormezano \& Gibbs, 1988). The signal from the phototransistor was amplified and transmitted to an analog-to-digital converter (10-msec sample rate) installed in the computer.

To transduce HR, a wound clip was attached to the skin on the left haunch about $40 \mathrm{~mm}$ from the spine and to the right shoulder about $40 \mathrm{~mm}$ from the spine. The two electrodes were separated by approximately $150 \mathrm{~mm}$. Electrolyte gel (Hewlett-Packard Redux Creme for electrocardiography) was applied to the skin and wound clips to improve the signal quality. Leads attached to wound clips carried the HR signal to a preamplifier mounted in the chamber and, subsequently, to a MacLab 8s v1 0.5 (software: Chart v3.5.2/s) and Macintosh Performa 5400/180 computer, where the frequency and interbeat interval of each rabbit's HR were recorded.

\section{Procedure}

All the rabbits received 1 day of preparation, 2 days of recovery, 1 day of adaptation, and 19 days of training and testing. On the preparation day, hair surrounding the rabbit's right eye was re- 
moved, and a small loop of surgical silk (000 Dynex) was sutured into the NM of the rabbit's right eye. In addition, a $2-\mathrm{cm}^{2}$ patch of hair was shaved from the left haunch and the right shoulder. On the adaptation day, the rabbits were placed in the conditioning apparatus for $60 \mathrm{~min}$, but neither a CS nor a US was presented.

Conditional discrimination training. Following adaptation, all the animals received 10 days of training in a conditional discrimination. The daily schedule consisted of 10 pairings of the target stimulus $(\mathrm{X})$ with the US during presentation of one feature cue $(\mathrm{A} \rightarrow \mathrm{X}+)$, alternated with 10 nonreinforced presentations of the target stimulus during presentation of a second feature cue $(B \rightarrow X-)$. The trials were administered in random order, with the exception that no more than three trials containing the same feature cue occurred consecutively. For half of the animals, A was the tone, and B was the white noise. For the rest of the animals, the feature cues were reversed; A was the noise, and $B$ was the tone.

The duration of each feature cue was varied randomly from trial to trial, ranging from 60 to $70 \mathrm{sec}(M=65 \mathrm{sec})$. The interval between the onset of the feature cue and the onset of the target stimulus was systematically manipulated across four values-specifically, $0,5,15$, and $45 \mathrm{sec}$. The corresponding groups $(n=8)$ were designated as Groups $0,5,15$, and 45 , respectively. Thus, for Group 0 , the onsets of the feature cue and the target stimulus were simultaneous. For the remaining groups, there was a serial relationship between the feature cue and the target stimulus. The duration of the target stimulus $(\mathrm{X})$ was $400 \mathrm{msec}$, and, on $\mathrm{A} \rightarrow \mathrm{X}+$ trials, the inter$\mathrm{val}$ between the onset of $X$ and that of the US was also $400 \mathrm{msec}$. Thus, the offset of $X$ coincided with onset of the US on $A \rightarrow X+$ trials. The intertrial interval (ITI) between the offset of the feature cue on one trial and the onset of the feature cue on the next trial ranged from 60 to $70 \sec (M=65 \mathrm{sec})$.

Feature cue testing. On Days 11,12 , and 13, each group received five $\mathrm{A} \rightarrow \mathrm{X}+$ and five $\mathrm{B} \rightarrow \mathrm{X}-$ trials of the same type as those they had received in training. In addition, all the animals received five A-alone trials and five B-alone trials. The tests allowed the recording of HR during the feature cues without intrusion by either the target stimulus $X$ or the US.

Feature-target interval testing. On Days 14, 16, and 18, each group received training identical to that used in initial discrimination training. On Days 15, 17, and 19, all the animals were presented with 32 nonreinforced test trials. These consisted of 8 trials of each feature-target interval-namely, $0,5,15$, and $45 \mathrm{sec}$. For each interval, there were $4 \mathrm{~A} \rightarrow \mathrm{X}$ trials and $4 \mathrm{~B} \rightarrow \mathrm{X}$ trials. The different types of trials were presented in random order.

\section{Response Definition}

A CR in the NM system was defined as any extension of the NM exceeding $0.5 \mathrm{~mm}$ initiated during a 400 -msec period following the onset of the $\mathrm{X}$ stimulus. Moreover, responding during $\mathrm{X}$ was corrected for the opportunity to respond, by including only trials on which the rabbit had not previously responded during the feature cue, thus preventing earlier CRs from masking the initiation of a $\mathrm{CR}$ during the $\mathrm{X}$ stimulus.

On A-alone and B-alone trials, the NM response was recorded during a 5-sec period immediately after the onset of the feature cue. This interval matched the interval used for recording HR following the onset of feature cues. In addition to providing comparable intervals for the NM and the HR recordings, the use of a 5-sec period was based on previous findings that, in conditional discriminations, the initiation of NM responses to feature cues is distributed across at least a 5-sec period, unlike the more concentrated initiation of NM responses to the target stimulus (Kehoe et al., 1987).

On $\mathrm{A}$-alone and $\mathrm{B}$-alone trials, $\mathrm{HR}$ was recorded during three periods: (1) for $4 \mathrm{sec}$ immediately before stimulus onset, (2) for $5 \mathrm{sec}$ immediately after stimulus onset, and (3) for another $5 \mathrm{sec}$ beginning 40 sec after stimulus onset. A heartbeat was defined as the interval between successive R-waves, provided that the interval was less than $400 \mathrm{msec}(\geq 2.5$ beats per second $)$ and greater than $180 \mathrm{msec}$ ( $\leq 5.5$ beats per second). This range restriction was imposed to eliminate movement-related artifacts that caused the software to either interpret noise in the recording as a series of rapid heartbeats or miss small R-waves, thus doubling the apparent interbeat interval. Each heartbeat was converted to an instantaneous HR (beats per second). The average of all the heartbeats during the period before the stimulus onset was used as the baseline.

\section{Results}

In all statistical analyses, the rejection level was set according to a Type 1 error rate of .05 . One animal in Group 45 developed an eye infection, and eyelid responding could not be recorded for that animal during initial acquisition training (Days $1-10$ ). However, its eyelid response data were available later, during interval testing.

\section{Acquisition of Eyelid Responding}

Figure 1 shows the percentage of trials containing eyelid CRs at two points in $\mathrm{A} \rightarrow \mathrm{X}+$ and $\mathrm{B} \rightarrow \mathrm{X}$ - trials: (1) following the onset of the feature cue (A or $B$ ) and (2) during the target stimulus $(\mathrm{X})$. There is a separate panel for each group. For each measurement point, a mean is plotted for each day of initial conditional discrimination training (Days 1-10), another mean is plotted for the feature cue tests ( $\mathrm{T} 1$ ), and another mean is plotted for the training trials during feature-target interval testing (T2). In the case of Group 0 , it was only possible to observe responding to $A$ and $B$ in isolation from $X$ during feature cue testing ( $\mathrm{Tl}$ ). During initial training (Days $1-10$ ) and the T2 stage, the data for Group 0 plotted in Figure 1 were based on the $\mathrm{AX}+$ and $\mathrm{BX}-$ training trials, in which the onset of $A$ and $B$ were simultaneous with $X$, thus precluding the separation of the CRs to the feature cues versus the target stimulus.

Inspection of Figure 1 reveals that all four groups showed differential eyelid responding to some degree. With respect to the feature cues, differentiation diminished as the feature-target interval used in training increased. For example, during the testing of the feature cues, Group 0 showed the highest level of responding tc the A cue $(M=54 \%)$ contrasted with a low level of responding to the $\mathrm{B}$ cue $(M=11 \%)$. For the longer feature-target intervals, the CR likelihood to the A cue declined, and there was some evidence that responding tc the B cue increased. In Group 15, the discrimination was generally robust but did briefly disappear during the feature cue tests ( $\mathrm{T} 1$ ). At the longest feature-target interval. Group 45 consistently showed low, undifferentiated levels of eyelid responding to the feature cues, hovering arounc $15 \%$ CRs. Statistical comparisons confirmed that there was a significant interaction of groups (linear trend) $X$ stimulus (A vs. B) in initial acquisition training [Days 1-10: $\left.F(1,19)=17.42, M S_{\mathrm{e}}=1,267.5\right]$, feature cue testing (T1) $\left[F(1,27)=21.38, M S_{\mathrm{e}}=232.7\right]$, and interval testing (T2) $\left[F(1,20)=6.98, M S_{\mathrm{e}}=190.1\right] .^{1}$

Examination of eyelid responding to the target stimulus $\mathrm{X}$ revealed that conditional control appeared in all the groups. For example, at the end of the experiment. 

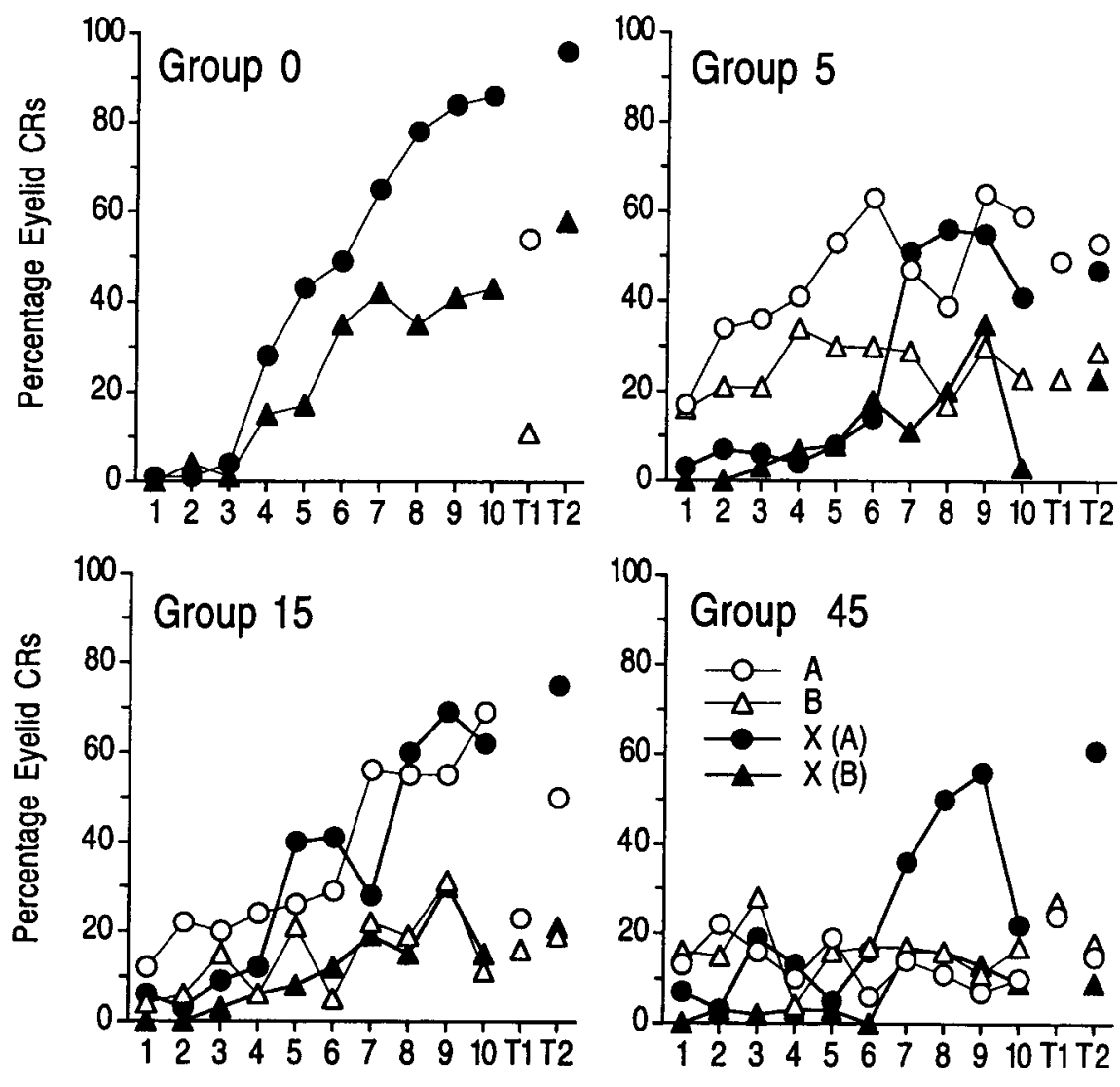

Day/Phase

Day/Phase

Figure 1. Mean percentage of conditioned responses (CRs) for the nictitating membrane system following the onset of $A$ and $B$ feature cues (open symbols) and during the target stimulus $X$ (filled symbols) in Experiment 1 . A mean is plotted for each day of initial conditional discrimination training (Days 1-10) for the feature cue tests (T1) and for feature-target interval testing (T2). For Group 0 , responding to $A$ and $B$ in isolation from $X$ could only be plotted during feature cue testing ( $T 1$ ).

CR likelihood during $\mathrm{X}$ in the presence of $\mathrm{A}$ was $70 \%$, as opposed to $28 \%$ in the presence of $\mathrm{B}$. This conditional control was significant in initial acquisition training $\left[F(1,26)=58.80, M S_{\mathrm{e}}=1,039.3\right]$ and interval testing (T2) $\left[F(1,27)=39.51, M S_{\mathrm{e}}=688.4\right]$. The degree of differentiation appeared relatively constant across groups. Any apparent interaction of groups (linear trend) $\times$ stimulus (A vs. B) failed to reach significance $\left(F<1, M S_{\mathrm{e}}=\right.$ $1,039.3)$.

\section{Interval Tests}

Although all the groups attained similar levels of conditional responding during presentation of the target stimulus, the interval tests revealed that this responding was very sensitive to the feature-target interval. Figure 2 depicts the $C R$ likelihood during $X$ on test trials as a function of the feature-target interval. For each group, the maximum level of responding appeared for the interval used on training trials, except for Group 15, in which max- imum responding occurred at the 5-sec interval. As the test interval deviated from the training interval, the level of responding, particularly on $\mathrm{A} \rightarrow \mathrm{X}$ trials, declined progressively. Statistical tests confirmed that the test interval (linear and quadratic trends) interacted significantly with groups (linear trend) and stimulus [A vs. B; $F \mathrm{~s}(1,27)=$ 50.16 and $11.39, M S_{\mathrm{e}}=163.6$ and 157.4].

The degree of temporal specificity was particularly pronounced in the groups trained with the shorter featuretarget intervals. The simultaneous group, Group 0 , showed a steep downward gradient in responding during $X$ on both $\mathrm{AX}$ and $\mathrm{BX}$ trials as the interval was increased from 0 to 5,15 , and $45 \mathrm{sec}$. In Group 5, the gradient was approximately symmetric around its training interval of $5 \mathrm{sec}$. That is, there were large decrements in responding when the interval was either shortened to $0 \mathrm{sec}$ or increased to $15 \mathrm{sec}$. In contrast, Groups 15 and 45 showed gradients with shallower slopes. In Group 15, the point of maximum responding appeared to have been displaced 

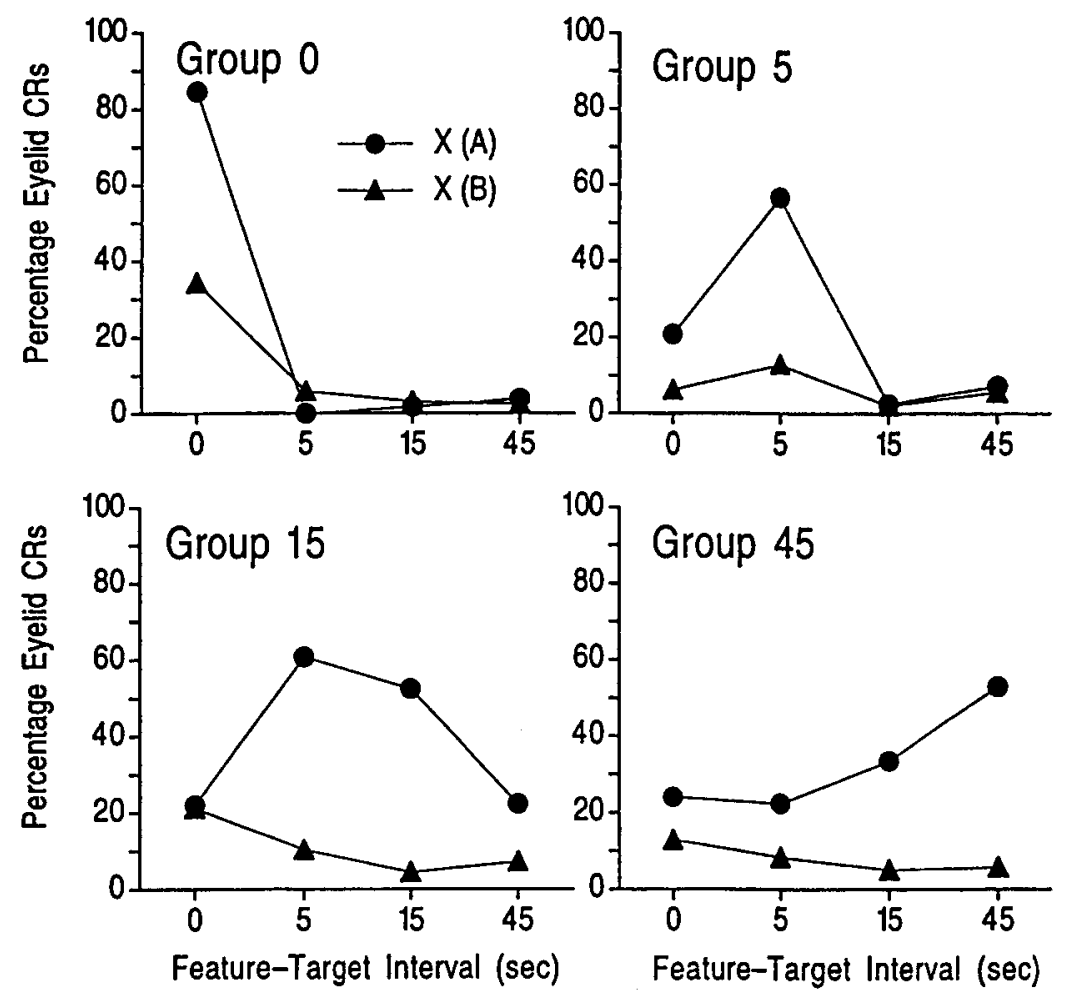

Figure 2. Mean percentage of conditioned responses (CRs) during presentation of $X$ in $A \rightarrow X$ and $B \rightarrow X$ test trials as a function of the feature-target interval in Experiment 1.

away from its training interval and toward the 5 -sec value. In Group 45, responding was maximal at its training interval of $45 \mathrm{sec}$.

Statistical comparisons confirmed the shapes of the gradients shown in Figure 2. For Group 0, there was a significant linear decline and, also, a quadratic component in performance as a function of the A-X test interval $\left[F \mathrm{~s}(1,27)=102.08\right.$ and $88.61, M S_{\mathrm{e}}=229.3$ and 147.3$]$. Similarly, for Group 5, there were both significant linear and quadratic trends in responding across test intervals $\left[F_{\mathrm{S}}(1,27)=9.30\right.$ and $5.10, M S_{\mathrm{e}}=229.3$ and 147.3]. In the case of Group 15, there was a significant quadratic trend in the performance across tests intervals $[F(1,27)=$ $\left.20.94, M S_{\mathrm{e}}=147.3\right]$. Finally, for Group 45, there were significant linear increases in responding as a function of the test interval $\left[F(1,27)=4.83, M S_{\mathrm{e}}=229.3\right]$, plus a quadratic trend $\left[F(1,27)=5.60, M S_{\mathrm{e}}=147.3\right]$.

\section{Heart Rate Responses to the Feature Cues}

In the examination of eyelid responding, differential responding occurred to the onset of A versus the onset of B in Groups 0, 5, and 15, but not in Group 45. Differentiation in HR followed a similar pattern. Figure 3 shows HR during two periods within presentation of the feature cues. HR is expressed as a percentage of change relative to the resting HR recorded for $4 \mathrm{sec}$ before cue onset. Points $1-5$ on the abscissa designate the mean change in HR in each of five 1-sec epochs following onset of the fea- ture cues. The sixth point designates the change in HR averaged across five $1-\mathrm{sec}$ epochs starting $40 \mathrm{sec}$ after the onset of the $A$ and $B$ cues, thus providing an estimate of HR near the end of the feature cues.

Examination of Figure 3 reveals two key features in the pattern of $\mathrm{HR}$ immediately following onset of the feature cues. First, Groups 0, 5, and 15 showed initial deceleration in HR during A, which tended to accelerate to levels above baseline in Groups 0 and 15. Group 45's HR showed only the accelerative component. All four groups showed negligible initial responding during $B$, which then accelerated to levels above baseline. Second, evidence of differentiation also appeared in Groups 0,5 , and 15 . Specifically, the HR during presentation of the A feature cue was below that during the B feature cue. The largest and most consistent difference occurred in Group 5.

Statistical comparisons largely confirmed the patterns seen in Figure 3. Specifically, HR showed a significant linear upward trend across epochs $[F(1,28)=26.32$, $\left.M S_{\mathrm{e}}=38.0\right]$. There was also significant differentiation in responding to $\mathrm{A}$ versus $\mathrm{B}\left[F(1,28)=7.48, M S_{\mathrm{e}}=48.8\right]$. Most important, there was a three-way interaction of epoch (linear trend) $\times$ stimulus $(A$ vs. $B) \times$ group [quadratic trend; $F(1,28)=12.67, M S_{\mathrm{e}}=5.3$ ]. This interaction appears to reflect the large differentiation in Group 5 , as compared with the other groups. Follow-up tests confirmed that Group 5's differentiation was statistically significant $\left[F(1,28)=11.34, M S_{\mathrm{e}}=5.3\right]$. Among the other 

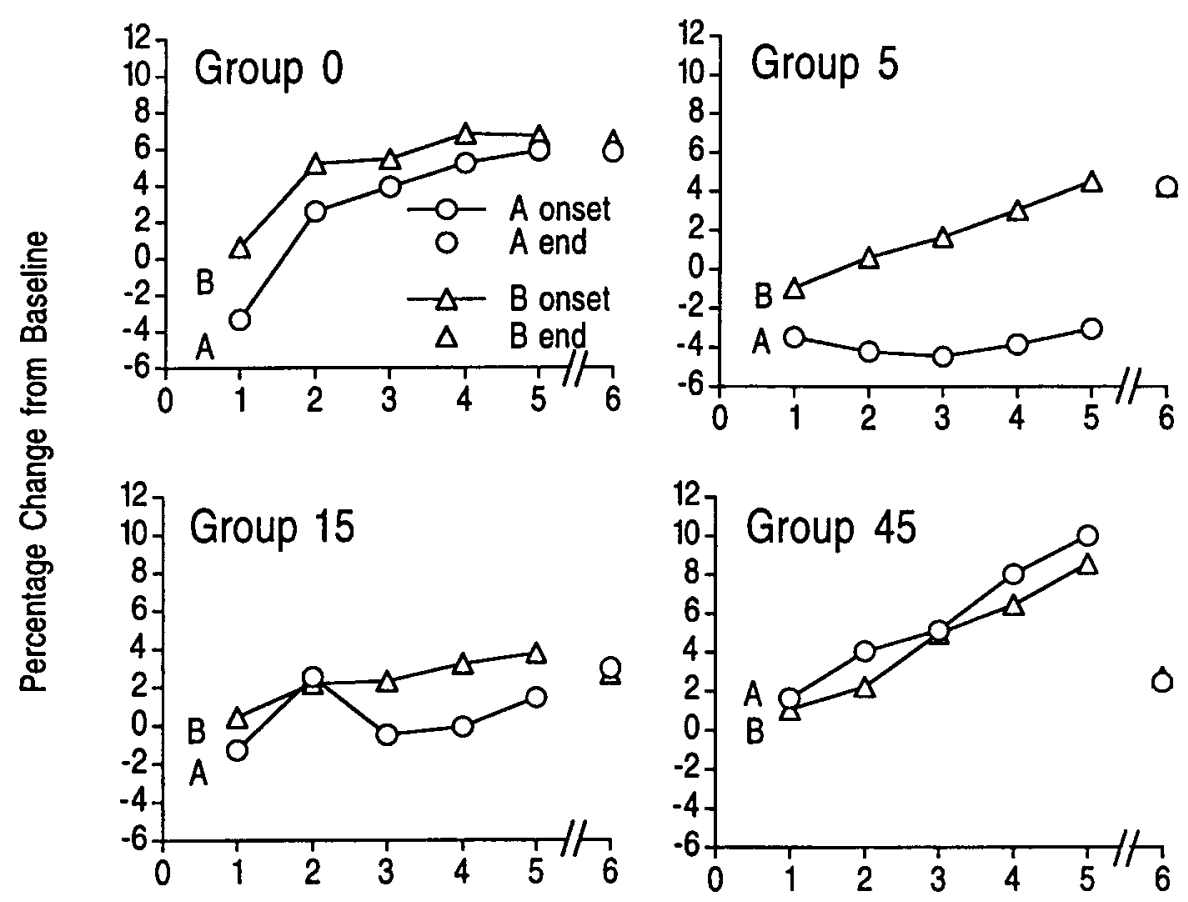

\section{Recording Epochs Following Feature Cue Onset}

Figure 3. Mean heart rate (HR) on $A$ and $B$ test trials expressed as a percentage of change relative to the resting $H R$ in Experiment 1. Points 1-5 depict $H R$ in each of five 1-sec epochs following cue onset. Point 6 designates HR averaged across five 1-sec epochs starting 40 sec after cue onset.

groups, Group 0's differentiation approached the declared level of significance $\left[F(1,28)=3.99, M S_{\mathrm{e}}=5.3\right.$, $p<.06]$, and the small differentiation apparent in Group 15 failed to attain significance $[F(1,28)=1.83$, $\left.M S_{\mathrm{e}}=5.3, p>.10\right]$. Group 45 's responding showed no evidence of differentiation $\left(F<1, M S_{\mathrm{e}}=5.3\right)$.

Examination of $\mathrm{HR}$ at the end of the feature cues revealed that all the groups showed some acceleration relative to the prestimulus baseline. The magnitude of the acceleration was a descending function of the featuretarget interval used in training $\left[F(1,28)=7.29, M S_{\mathrm{e}}=\right.$ 78.2]. That is, Groups $0,5,15$, and 45 showed mean accelerations of $6 \%, 4 \%, 3 \%$, and $3 \%$, respectively. This acceleration appeared to be identical for both feature cues. Any apparent differentiation failed to attain significance $\left(F<1, M S_{\mathrm{e}}=24.3\right)$.

\section{Discussion}

In summary, we examined two discriminations in this experiment and found the following: First, the animals showed acquisition of a simple discrimination between the feature cues in both the eyelid and the HR systems. The magnitude of the discrimination tended to diminish across groups. Whereas Groups 0,5 , and 15 showed evidence of differential responding to A versus $B$ in both response systems, Group 45 failed to show evidence of discriminative responding in either response system. Second, the animals in all four groups showed acquisition of conditional eyelid responding to the target stimulus $\mathrm{X}$ to a similar degree. However, when the feature-target interval was manipulated in testing, temporal specificity appeared in all four groups. That is, responding to the target stimulus progressively declined as the feature-target interval was shifted away from the value used in training.

\section{EXPERIMENT 2}

Experiment 2 entailed a systematic replication of Groups 5 and 45, with two differences. First, the assignment of visual and auditory events as feature cues and target stimuli was counterbalanced, relative to Experiment 1. Second, in Experiment 1, the HR response, if any, to the target stimulus was not measured. Given that both eyelid and HR conditioning occurred during presentation of the feature cues, we wished to determine whether HR as well as eyelid conditioning occurred to the target stimulus. As a means of separating the HR response to the target stimulus from the HR response to the onset of the feature cues, HR was measured during the $X$ stimulus on test trials in which the $X$ stimulus was presented $45 \mathrm{sec}$ after the onset of the feature cues. In Experiment 1 , it was seen that $\mathrm{HR}$ during that portion of the 
feature cues in all groups was slightly elevated but not differentiated between the $\mathrm{A}$ and the $\mathrm{B}$ cues.

\section{Method}

Subjects

The subjects were 16 female, albino rabbits.

\section{Apparatus and Procedure}

Unless otherwise mentioned, the apparatus and procedure were identical to those of Experiment 1. The two feature cues were $76 \mathrm{sec}$ of complete darkness (houselight off) and $76 \mathrm{sec}$ of a flashing houselight $(20 \mathrm{~Hz})$, respectively. The ambient visual condition during the ITI was houselight on. The target stimulus was a $400-\mathrm{msec}$ $1000-\mathrm{Hz}, 94-\mathrm{dB}$ tone. All the rabbits received 1 day of preparation, 2 days of recovery, 1 day of adaptation, and 25 days of training and testing.

Conditional discrimination training. Following adaptation, all the animals received 20 days training in a conditional discrimination. The daily schedule contained $10 \mathrm{~A} \rightarrow \mathrm{X}+$ trials, alternated randomly with $10 \mathrm{~B} \rightarrow \mathrm{X}-$ trials. The animals were assigned to two groups, designated as Groups V5 and V45, which were trained with 5 -sec and 45-sec feature-target intervals, respectively. The " $\mathrm{V}$ " in the label indicated the visual nature of the feature cues and distinguished each group in this experiment from its counterpart in Experiment 1 . The ITI between the offset of the feature cue on one trial and the onset of the feature cue on the next trial was $76 \mathrm{sec}$.

Testing. On Days 22 and 24, each group received training identical to that used in initial discrimination training. On Days 21, 23, and 25 , all the animals were presented with 32 nonreinforced test trials. These consisted of 4 trials of the following feature target intervals: $5,15,30$, and $45 \mathrm{sec}$. For each interval, there were $4 \mathrm{~A} \rightarrow \mathrm{X}$ trials and $4 \mathrm{~B} \rightarrow \mathrm{X}$ trials. The different types of trials were presented in random order. On the $45-\mathrm{sec}$ interval trials, HR was measured during four epochs: (1) for $4 \mathrm{sec}$ immediately before the onset of the feature cue, (2) for $5 \mathrm{sec}$ immediately after cue onset, (3) for another $4 \mathrm{sec}$ beginning $41 \mathrm{sec}$ after cue onset, and (4) another $5 \mathrm{sec}$ immediately after the onset of the target stimulus $X$, which occurred $45 \mathrm{sec}$ after onset of the feature cue.

\section{Results and Discussion}

In all the statistical analyses, the rejection level was set according to a Type 1 error rate of .05. One animal in
Group V5 injured itself at the end of initial training and had to be removed from the experiment during the interval testing, thus reducing that group to 7 animals.

\section{Acquisition of Eyelid Responding}

Figure 4 shows the percentage of trials containing eyelid CRs at two points in $\mathrm{A} \rightarrow \mathrm{X}+$ and $\mathrm{B} \rightarrow \mathrm{X}$ - trials: (1) during a 400-msec interval immediately following the onset of the feature cue (A or B) and (2) during the $400-\mathrm{msec}$ target stimulus $(X)$.

An inspection of Figure 4 largely confirms the results for the corresponding groups in Experiment 1 . Specifically, Group V5 showed differential eyelid responding to the feature cues (A vs. B), whereas Group V45 showed no evidence of acquisition of eyelid CRs to either the $A$ or the B cue. Statistical analysis confirmed that there was a significant interaction of groups (V5 vs. V45) $\times$ stimulus [A vs. $\mathrm{B} ; F(1,14)=5.70, M S_{\mathrm{e}}=1,062.4$ ]. In contrast, conditional responding to the target stimulus $X$ was evident in both groups. The level of differentiation in Group V5 appeared larger than that in Group V45. Statistical comparisons confirmed that there was significantly greater responding to $\mathrm{X}$ in the presence of $\mathrm{A}$ than in the presence of $\mathrm{B}\left[F(1,14)=20.47, M S_{\mathrm{e}}=719.1\right]$. However, the groups (V5 vs. V45) $\times$ stimulus (A vs. B) interaction was not significant $\left[F(1,14)=2.27, M S_{\mathrm{e}}=\right.$ $719.1, p>.10]$. Later, during testing, the differentiation in Group V45 grew larger and approached that of Group V5. Specifically, in Group V45, the mean difference in responding to $X$ during $A$ versus $B$ was 30 percentage points, as compared with the difference in Group V5, which was 41 percentage points.

\section{Interval Tests}

Figure 5 depicts the $\mathrm{CR}$ likelihood during $\mathrm{X}$ on test trials as a function of the feature-target interval. The maximum level of responding appeared for the interval used on training trials. As the test interval deviated from the
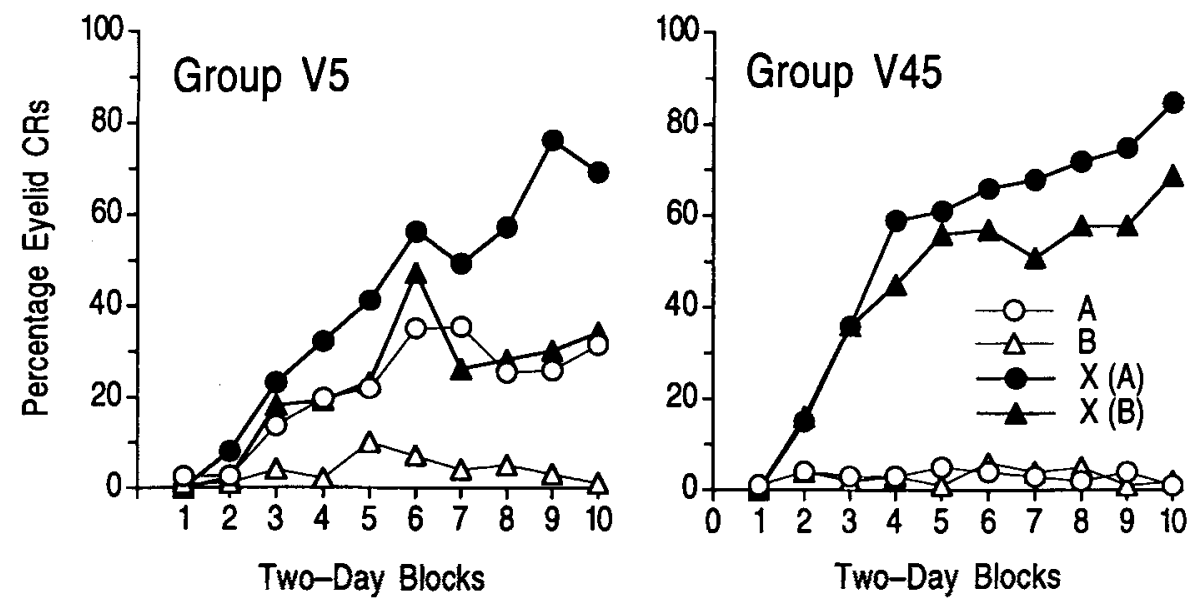

Figure 4. Mean percentage of conditioned responses (CRs) for the nictitating membrane system following the onset of $A$ and $B$ feature cues (open symbols) and during presentation of the target stimulus $X$ (filled symbols) in Experiment 2. A mean is plotted for each 2-day block of initial training in the conditional discrimination (Days 1-20). 


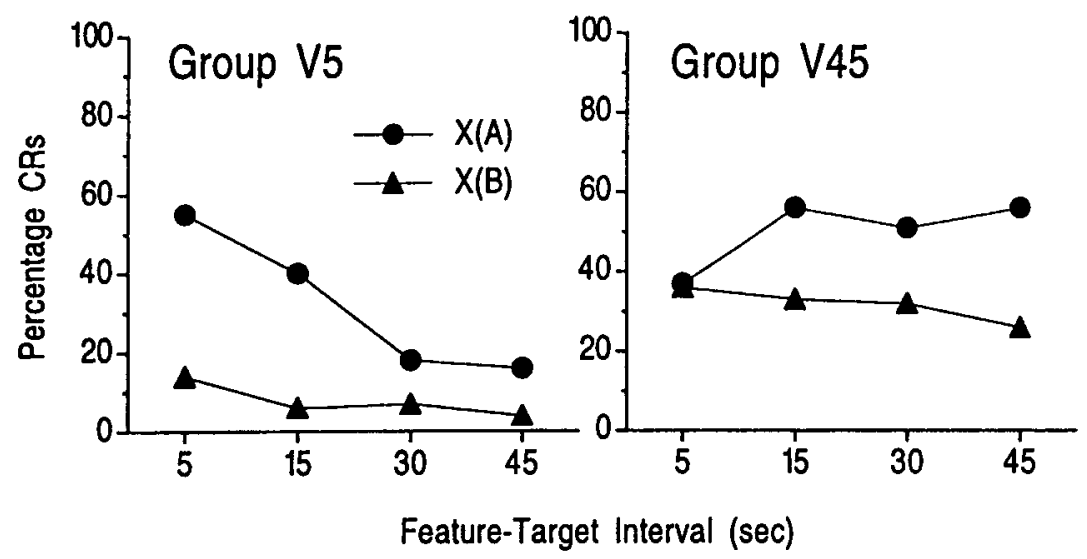

Figure 5. Mean percentage of conditioned responses (CRs) during presentation of $X$ in $A \rightarrow X$ and $B \rightarrow X$ test trials as a function of the feature-target interval in Experiment 2.

training interval, the level of responding, particularly on $A \rightarrow X$ trials, tended to decline. As was seen in Experiment 1 , the gradient was steeper for the group trained with the shorter feature-target interval (Group V5) than for the group trained with the longer feature-target interval (Group V45). Statistical tests confirmed a three-way interaction of test interval (linear trend) $\times$ groups (V5 vs. V45) $X$ stimulus [A vs. B; $\left.F(1,13)=6.98, M S_{\mathrm{e}}=484.2\right]$. For Group V5, there was a significant downward linear trend across test intervals $\left[F(1,13)=27.22, M S_{\mathrm{e}}=186.3\right]$. For Group V45, the apparent increase in responding across test intervals failed to reach significance $\left(F<1, M S_{\mathrm{e}}=186.3\right)$.

\section{Heart Rate Responding}

Figure 6 shows HR during three epochs during test trials in which the feature-target interval was $45 \mathrm{sec}$. HR is expressed as a percentage of change relative to the resting HR recorded for $4 \mathrm{sec}$ before stimulus onset. The left-hand set of points depicts the first 12 heartbeats after the onset of the feature cues, the center set of points depicts 12 heartbeats starting $41 \mathrm{sec}$ after the onset of the feature cues, and the right-hand set of points represents the change in HR for 12 beats following onset of the target stimulus $X$. The unit of analysis was switched from the 1 -sec epochs in Experiment 1 to a beat-by-beat unit, in order to detect any transient changes in HR during the 400-msec target stimulus. (To determine the correspondence between a beat-by-beat unit and the $1-\mathrm{sec}$ unit, a beat-by-beat analysis was conducted on Experiment I's HR data. It revealed the same pattern of results for the feature cues as that seen using 1-sec epochs.)

An examination of Figure 6 largely confirms the pattern of responding seen following the onset of the feature cues in the corresponding groups in Experiment 1. That is, Group V5 showed differential HR conditioning following the onset of the feature cues. There was a deceleration in HR during the A cue, but not during the B cue $\left[F(1,13)=12.17, M S_{\mathrm{e}}=4.4\right]$. In contrast, Group V45 showed no evidence of a change following the onset of either feature cue. Any apparent small differences in responding to the feature cues in Group V45 were not statistically significant $\left(F<1, M S_{\mathrm{e}}=4.4\right)$. Unlike Experiment 1 , however, neither group showed an overall tendency for HR to accelerate following the onset of the feature cues.

Examination of HR near the end of the feature cues, but prior to the onset of the target stimulus, suggested that Group V5's overall HR was accelerated and that some differentiation remained between the $\mathrm{A}$ and the $\mathrm{B}$ cues. However, these differences failed to even approach statistical significance $\left(M S_{\mathrm{e}}=90.6, p \mathrm{~s}>.10\right)$. Any apparent differences between Groups V5 and V45 also failed to approach significance.

Finally, HR following the onset of X showed some significant differences between the two groups across time $\left[F(1,13)=9.57, M S_{\mathrm{e}}=4.9\right]$. Specifically, there was a transient deceleration in Group V45, in which the $\mathrm{X}$ stimulus occupied the same time period that it had on training trials. This deceleration appeared to be confined to the second and third beats and it appeared to be undifferentiated between the $A \rightarrow X$ and the $B \rightarrow X$ trials. In statistical comparisons, the deceleration appeared as a significant upward trend across successive heartbeats $\left[F(1,13)=8.13, M S_{\mathrm{e}}=4.9\right]$. In Group V5, in which the $\mathrm{X}$ stimulus was displaced well away from its customary time period, there was a less pronounced pattern of changes in the HR following the onset of X. Statistically, there were no significant changes in $\mathrm{HR}$ across successive beats $\left[F(1,13)=2.46, M S_{\mathrm{e}}=4.9, p>.10\right]$. Although there appeared to be a deceleration on $A \rightarrow X$ trials versus $B \rightarrow X$ trials in Group V5, this apparent differentiation in responding to the $\mathrm{X}$ stimulus failed to reach significance $\left[F(1,13)=1.98, M S_{\mathrm{e}}=92.4, p>.10\right]$.

The apparent absence of differential HR responding to the $\mathrm{X}$ stimulus is not surprising, given the $400-\mathrm{msec}$ duration of the $X$ stimulus. Previous research has shown that CS-US intervals around $400 \mathrm{msec}$ yield only modest HR conditioning in the rabbit (Meredith \& Schneiderman, 1967; Powell \& Levine-Bryce, 1988). Hence, 


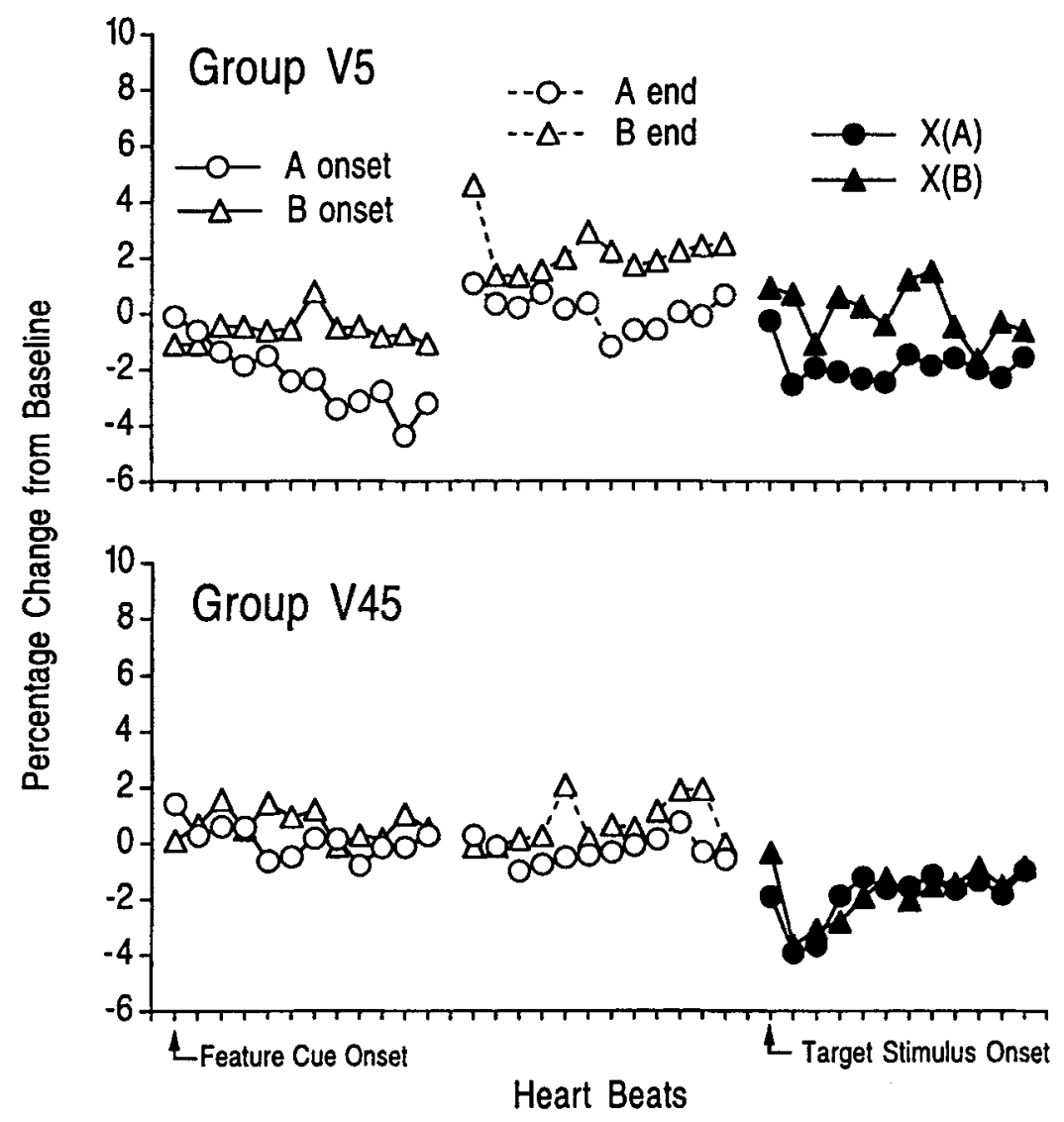

Figure 6. Mean heart rate (HR) on $A$ and B test trials in Experiment 2 expressed as a percentage of change relative to the resting HR for 12 heartbeats following (1) the onset of the feature cues, (2) a point starting 41 sec after the onset of the feature cues, and (3) the onset of the target stimulus $X$.

conditional control of HR may have been hard to achieve under these parameters.

\section{GENERAL DISCUSSION}

Recall that the first issue under scrutiny concerned the time constraints on the action of feature cues in their conditional control over responding to the target stimulus. The present results demonstrated that conditional discriminations can be acquired in eyelid conditioning with relative ease and, to about the same degree, across a huge range of feature-target intervals. With the possible exception of Group V45, CR likelihood to the target stimulus $X$ in $A \rightarrow X+$ trials reached a level that was about 43 percentage points higher than that in $B \rightarrow X$ - trials within 8-9 days of training. The overall speed of CR acquisition to the $\mathrm{X}$ stimulus compares favorably with that seen in the rabbit NM preparation when training entails 5-10 CS-US pairings per session, using CS-US intervals of 250-400 msec (Kehoe \& Gormezano, 1974; Macrae \& Kehoe, 1999).
It would be a mistake, however, to conclude that conditional eyelid responding was insensitive to the featuretarget interval. Altering the feature-target interval on test trials yielded a temporal gradient of eyelid responding during $X$ that was centered on the interval used in training. Hence, these results converge with previous findings that there is temporal specificity in the conditional control exercised by long feature cues in appetitive conditioning of rats (Holland et al., 1997) and by brief cues in aversive conditioning of rabbits (Weidemann et al., 1999).

The second issue concerned the significance of CRs, or the lack thereof, during feature cues. The evidence here indicated that simple conditioning of the feature cues occurred in a fashion that was not obviously related to the strength of their conditional control. Whereas acquisition of conditional control was not strongly influenced by the feature-target interval, the acquisition of discriminative responding to $\mathrm{A}$ and $\mathrm{B}$ in both the eyelid and the HR systems was sensitive to the temporal relationship of the feature cues to the target stimulus and the US. In brief, a contiguity gradient was apparent. Abso- 
lute responding and differentiation were greatest at the shorter intervals but disappeared entirely when training was conducted with the 45 -sec interval.

These gradients help to establish the outer limit of conditioning for both response systems. For the rabbit eyelid response, acquisition of a CR to a single CS is usually limited to CS-US intervals ranging over a few seconds (Gormezano, Kehoe, \& Marshall, 1983; Kehoe, Cool, \& Gormezano, 1991). However, CR acquisition has been extended over a wider range of CS-US intervals when two CSs have been presented in sequence prior to a US $(\mathrm{A} \rightarrow \mathrm{X}+)$. Provided that the second stimulus $(\mathrm{X})$ is close to the US, CR acquisition to the A stimulus has been obtained at CS-US intervals stretching up to values of 12-18 sec (Kehoe, Feyer, \& Moses, 1981; Kehoe, Gibbs, Garcia, \& Gormezano, 1979; Kehoe et al., 1987). Similarly, secondorder conditioning of the rabbit eyelid response has been obtained at intervals between the second-order and the first-order CSs of up to, at least, $8 \mathrm{sec}$ (Gibbs, Cool, Land, Kehoe, \& Gormezano, 1991). However, it has never been clear how far two CSs could be separated before CR acquisition to the A stimulus would disappear. Similarly, for the HR response, the maximum CS-US interval for simple conditioning has not previously been known (Manning, Schneiderman, \& Lordahl, 1969; Meredith \& Schneiderman, 1967; Powell \& Levine-Bryce, 1988; Powell, Lipkin, \& Milligan, 1974). On the basis of the present data, it would appear that the outer boundary for both response systems lies somewhere between 20 and $45 \mathrm{sec}$.

One of the purposes of these experiments was to determine the relationship between (1) HR conditioning to the feature cues and (2) conditional eyelid responding to the target stimulus. As can now be seen, there was certainly not a one-to-one correspondence. At the $45-\mathrm{sec}$ featuretarget interval, HR conditioning was not evident, but the conditional discrimination remained strong. On this basis, it is unclear whether HR should be accorded any special status as an index of any emotional, attentional, preparatory, or orienting processes operating in conditional discriminations. That is, the absence of HR CRs to the feature cues cannot be used to deny the existence of any preparatory process (see, e.g., Brandon \& Wagner, 1991; Wagner \& Brandon, 1989) or, by default, to confirm the role of any alternative process (see, e.g., Holland, 1983, 1992; Rescorla, 1985). Nevertheless, HR remains valuable as a measure that converges with the eyelid response on the associative processes that do operate during prolonged feature cues. Among other things, the ongoing nature of HR permits both tonic and phasic changes to be tracked over long periods.

Turning now to the mechanisms of conditional discrimination, the parallel in the contiguity gradients for CR acquisition to the feature cues in both response systems suggests that they share a temporal encoding of the feature cues. However, both gradients become theoretically perplexing when contrasted with the ability of the feature cues to acquire conditional control over eyelid responding with little, if any, diminution at long feature-target intervals. Had the acquisition of conditional control diminished dramatically at the longer feature-target intervals, it could have been easily concluded that the temporal encoding of the feature cue decayed over a $45-\mathrm{sec}$ period. Most theories of timing assume that the encoding of a stimulus decays over time, regardless of whether the encoding is depicted as a stimulus trace (Gormezano \& Kehoe, 1981; Hull, 1943; Kehoe et al., 1987; Pavlov, 1927, p. 39; Sutton \& Barto, 1981, 1990) or a short-term memory (Konorski \& Lawicka, 1959; Riley, Cook, \& Lamb, 1981; Roberts \& Grant, 1976). However, the apparent constancy in conditional control across groups, plus the temporal specificity of conditional control within each group, indicates that the encoding of the feature cues remained functional up to $45 \mathrm{sec}$. Hence, the question becomes, why did $\mathrm{CR}$ acquisition to the feature cues diminish at the longer feature-target intervals?

An answer to this question may lie in a closer look at the gradients obtained in testing of the feature-target intervals. Most notably, the groups trained with the longer feature-target intervals showed broader gradients than did the groups trained with the shorter intervals. From a psychophysical perspective, the increase in the breadth of the test interval gradients is hardly surprising. Judgments of time intervals typically become increasingly inaccurate as their duration increases (Church \& Gibbon, 1982; Gibbon, 1977, 1991). The successive portions of the encoding may become increasingly variable before decay of stimulus encoding becomes pronounced.

Such progressive variability could be deleterious to CR acquisition to the feature cues but have little effect on their ability to exert conditional control over responding to the target stimulus. Specifically, since Pavlov (1927, pp. 103104), it has been postulated that a CS gives rise to a cascade of hypothetical stimulus elements. Each element is assumed to acquire its own associative strength according to its contiguity with the US. In some recent models, the elicitation and timing of the CR depends on the summation of the associative strengths of overlapping elements (Desmond, 1990; Desmond \& Moore, 1988; Grossberg \& Schmajuk, 1989; Kehoe, Horne, \& Macrae, 1995; Sutton \& Barto, 1990; see Buhusi \& Schmajuk, 1999, for a specific application of this type of model to conditional discriminations). If the stimulus elements later in the encoding became increasingly variable, it would become more and more difficult for them to accumulate enough associative strength at any one time to yield an overt CR. Although such variability in time would hinder CR acquisition, the overall encoding of the feature cues could remain distinctive enough to allow them to exert conditional control over the elicitation of the eyelid CR by the large number of overlapping elements generated by the target stimulus as a result of its close relation to the US. 


\section{REFERENCES}

ASRATYAN, E. A. (1965). Compensatory adaptations, reflex activity and the brain. Oxford: Pergamon.

BarNet, R. C., \& MiLLER, R. R. (1996). Temporal encoding as a determinant of inhibitory control. Learning \& Motivation, 27, 73-91.

BLACK, A. H., \& DE TOLEDO, L. (1972). The relationship among classically conditioned responses: Heart rate and skeletal behavior. In A. H. Black \& W. F. Prokasy (Eds.), Classical conditioning II: Current research and theory (pp. 290-311). New York: Appleton-Century-Crofts.

Bouton, M. E. (1991). Context and retrieval in extinction and in other examples of interference in simple associative learning. In L. Dachowski \& C. F. Flaherty (Eds.), Current topics in animal learning: Brain, emotion, and cognition (pp. 25-49). Hillsdale, NJ: Erlbaum.

Brandon, S. E., \& Wagner, A. R. (1991). Modulation of a discrete Pavlovian conditioned reflex by a putative emotive Pavlovian conditioned stimulus. Journal of Experimental Psychology: Animal Behavior Processes, 17, 299-311.

Buhusi, C. V., \& Schmajuk, N. A. (1999). Timing in simple conditioning and occasion setting: A neural network approach. Behavioural Processes, 45, 33-57.

ChuRCH, R. M., \& GibBon, J. (1982). Temporal generalization. Journal of Experimental Psychology: Animal Behavior Processes, 8, 165-186.

Denniston, J. C., Cole, R. P., \& Miller, R. R. (1998). The role of temporal relationships in the transfer of conditioned inhibition. Journal of Experimental Psychology: Animal Behavior Processes, 24, 200-214.

DESMOND, J. E. (1990). Temporal adaptive responses in neural models: The stimulus trace. In M. Gabriel \& J. W. Moore (Eds.), Learning and computational neuroscience (pp. 421-456). Cambridge, MA: MIT Press.

DESMOND, J. E., \& Moore, J. W. (1988). Adaptive timing in neural networks: The conditioned response. Biological Cybernetics, 58, 405-415.

GiBBoN, J. (1977). Scalar expectancy theory and Weber's Law in animal timing. Psychological Review, 84, 279-325.

GiBBON, J. (1991). Origins of scalar timing. Learning \& Motivation, 22, 3-38.

Gibas, C. M., Cool, V., Land, T., Kehoe, E. J., \& Gormezano, I. (1991). Second-order conditioning of the rabbit's nictitating membrane response: Interstimulus interval and frequency of CS-CS pairings. Integrative Physiological \& Behavioral Science, 26, 282-295.

Gormezano, I. (1966). Classical conditioning. In J. B. Sidowski (Ed.), Experimental methods and instrumentation in psychology (pp. 385420). New York: McGraw-Hill.

Gormezano, I., \& GibBs, C. M. (1988). Transduction of the rabbit's nictitating membrane response. Behavior Research Methods, Instruments, \& Computers, 20, 18-21.

Gormezano, I., \& KeHOE, E. J. (1981). Classical conditioning and the law of contiguity. In P. M. Harzem \& M. D. Zeiler (Eds.), Advances in analysis of behavior: Vol. 2. Predictability, correlation, and contiguity (pp. 1-45). New York: Wiley.

Gormezano, I., Kehoe, E. J., \& Marshall, B. S. (1983). Twenty years of classical conditioning research with the rabbit. In J. M. Sprague \& A. N. Epstein (Eds.), Progress in psychobiology and physiological psychology (pp. 197-275). New York: Academic Press.

Grahame, N. J., Barnet, R. C., \& Miller, R. R. (1992). Pavlovian conditioning in multiple contexts: Competition between contexts for comparator status. Animal Learning \& Behavior, 20, 329-338.

Grahame, N. J., Hallam, S. C., Geier, L., \& Miller, R. R. (1990). Context as an occasion setter following either CS acquisition and extinction or CS acquisition alone. Learning \& Motivation, 21, 237-265.

Grossberg, S., \& Schmajuk, N. A. (1989). Neural dynamics of adaptive timing and temporal discrimination during associative learning. Neural Networks, 2, 79-102.

Holland, P. C. (1983). Occasion-setting in Pavlovian feature positive discriminations. In M. L. Commons, R. J. Herrnstein, \& A. R. Wagner (Eds.), Quantitative analyses of behavior: Discrimination processes (pp. 182-206). New York: Ballinger.

HollaND, P. C. (1992). Occasion setting in Pavlovian conditioning. In D. L. Medin (Ed.), The psychology of learning and motivation (Vol. 28 , pp. 69-125). San Diego: Academic Press.
Holland, P. C., Hamlin, P. A., \& Parsons, J. P. (1997). Temporal specificity in serial feature-positive discrimination learning. Journal of Experimental Psychology: Animal Behavior Processes, 23, 95-109.

Hul.L, C. L. (1943). Principles of behavior. New York: AppletonCentury-Crofts.

Kehoe, E. J., CoOl, V., \& Gormezano, I. (1991). Trace conditioning of the rabbit's nictitating membrane response as a function of CS-US interstimulus interval and trials per session. Learning \& Motivation, 22, 269-290.

KeHOE, E. J., Feyer, A.-M., \& Moses, J. L. (1981). Second-order conditioning of the rabbit's nictitating membrane response as a function of the CS2-CS1 and CS1-US intervals. Animal Learning \& Behavior, 9, 304-315.

Kehoe, E. J., Gibbs, C. M., Garcia, E., \& Gormezano, I. (1979). Associative transfer and stimulus selection in classical conditioning of the rabbit's nictitating membrane response to serial compound CSs. Journal of Experimental Psychology: Animal Behavior Processes, 5, 1-18.

KeHOE, E. J., \& GORMEZANO, I. (1974). Effects of trials per session on conditioning of the rabbit's nictitating membrane response. Bulletin of the Psychonomic Society, 4, 434-436.

KeHOE, E. J., HoRNE, A. J., \& MACRAE, M. (1995). Learning to learn: Real-time features and a connectionist model. Adaptive Behavior, 3 . 235-271.

Kehoe, E. J., Marshall-Goodell, B., \& Gormezano, I. (1987). Differential conditioning of the rabbit's nictitating membrane response to serial compound stimuli. Journal of Experimental Psychology: Animal Behavior Processes, 13, 17-30.

KImmel, H. D., \& RAY, R. L. (1978). Transswitching: Conditioning with tonic and phasic stimuli. Journal of Experimental Psychology: General, 107, 187-205.

KonORSKI, J., \& LAWICKA, W. (1959). Physiological mechanisms of delayed reactions: 1 . The analysis and classification of delayed reactions. Acta Biologiae Experimentalis, 19, 175-197.

LENNARTZ, R. C., \& WEINBERGER, N. M. (1994). A comparison of nonspecific and nictitating membrane conditioned responses: Additional support for two-factor theories. Psychobiology, 22, 5-15.

MACRAE, M., \& KeHOE, E. J. (1995). Transfer between conditional and discrete discriminations in conditioning of the rabbit nictitating membrane response. Learning \& Motivation, 26, 380-402.

MaCraE, M., \& KehOE, E. J. (1999). Savings after extinction in conditioning of the rabbit's nictitating membrane response. Psychobiology, 27, 85-94.

Manning, A. A., Schneiderman, N., \& Lordahl, D. S. (1969). Delay vs. trace heart rate classical discrimination conditioning in rabbits as a function of ISI. Journal of Experimental Psychology, 80, 225-230.

Meredith, A. L., \& Schneiderman, N. (1967). Heart rate and nictitating membrane classical discrimination conditioning in rabbits under delay versus trace procedures. Psychonomic Science, 9, 139-140.

Obrist, P. A., SutTerer, J. R., \& Howard, J. L. (1972). Preparatory cardiac changes: A psychobiological approach. In A. H. Black \& W. T. Prokasy (Eds.), Classical conditioning II: Current research and theory (pp. 312-340). New York: Appleton-Century-Crofts

Pavlov, I. P. (1927). Conditioned reflexes: An investigation of the physiological activity of the cerebral cortex (G. V. Anrep, Trans.). London: Oxford University Press.

Powell, D. A., \& Levine-Bryce, D. (1988). A comparison of two model systems of associative learning: Heart rate and eyeblink conditioning in the rabbit. Psychophysiology, 25, 672-682.

Powell, D. A., LiPkin, M., \& Milligan, W. L. (1974). Concomitant changes in classically conditioned heart rate and corneoretinal potential discrimination in the rabbit (Oryctolagus cuniculus). Learning \& Motivation, 5, 532-547.

Rescorla, R. A. (1985). Inhibition and facilitation. In R. R. Miller \& N. E. Spear (Eds.), Information processing in animals: Conditioned inhibition (pp. 299-326). Hillsdale, NJ: Erlbaum.

ResCorla, R. A., \& Solomon, R. (1967). Two-process learning theory: Relationships between Pavlovian conditioning and instrumental learning. Psychological Review, 74, 151-182.

Riley, D. A., COOK, R. G., \& LAMB, M. R. (1981). A classification and analysis of short-term retention codes in the pigeon. In G. H. Bower 
(Ed.), The psychology of learning and motivation: Advances in research and theory (Vol. 15, pp. 51-79). New York: Academic Press.

Roberts, W. A., \& GRaNT, D. S. (1976). Studies of short-term memory in the pigeon using the delayed matching-to-sample procedure. In D. L. Medin, W. A. Roberts, \& R. T. Davis (Eds.), Processes of animal memory (pp. 79-112). Hillsdale, NJ: Erlbaum.

SCandrett, J., \& Gormezano, I. (1980). Microprocessor control and A/D data acquisition in classical conditioning. Behavior Research Methods \& Instrumentation, 12, 120-125.

Schmajuk, N. A., Lamoureux, J. A., \& Holland, P. C. (1998). Occasion setting: A neural network approach. Psychological Review, 105, 3-32.

SCHNEIDERMAN, N. (1972). Response system divergencies in aversive classical conditioning. In A. H. Black \& W. F. Prokasy (Eds.), Classical conditioning II: Current research and theory (pp. 341-376). New York: Appleton-Century-Crofts.

Sutton, R. S., \& Barto, A. G. (1981). Toward a modern theory of adaptive networks: Expectation and prediction. Psychological Review, 88, 135-171.

Sutron. R. S., \& Barto, A. G. (1990). Time-derivative models of Pavlovian reinforcement. In M. Gabriel \& J. W. Moore (Eds.), Learning and computational neuroscience (pp. 497-537). Cambridge, MA: MIT Press.

Thompson, R. F., Donegan, N. H., Clark. G. A., Lavond. D. G., Lincoln, J. S., Madden, J., Mamounas, L. A., Mauk, M. D., \& MCCormick, D. A. (1987). Neuronal substrates of discrete, defensive conditioned reflexes, conditioned fear states, and their interactions in the rabbit. In I. Gormezano, W. F. Prokasy, \& R. F. Thompson (Eds.), Classical conditioning (3rd ed., pp. 371-399). Hillsdale, NJ: Erlbaum.
Wagner, A. R., \& Brandon, S. E. (1989). Evolution of a structured connectionist model of Pavlovian conditioning (AESOP). In S. B. Klein \& R. R. Mowrer (Eds.), Contemporary learning theories: Pavlovian conditioning and the status of traditional learning theory (pp. 149190). Hillsdale, NJ: Erlbaum.

Weidemann, G., Georgilas, A., \& Kehoe, E. J. (1999). Temporal specificity in patterning of the rabbit nictitating membrane response. Animal Learning \& Behavior, 27, 99-107.

WeidemanN, G., \& KehOE, E. J. (1997). Transfer and counterconditioning of conditional control in the rabbit nictitating membrane response. Quarterly Journal of Experimental Psychology, 50B, 295-316.

\section{NOTE}

1. The degrees of freedom varied across phases for the following reasons. For the analysis of responding to the onset of feature cues in acquisition training (Days $1-10$ ) and interval testing (T2), the data from Group 0 were not included, because responding to the onset of the feature cues could not be recorded during these periods. Thus, for the feature cues, only the data from the other three groups were included. In addition, in acquisition training, one other rabbit in Group 45 was not included in the analysis of NM data, because this animal contracted an eye infection during this period, and although it was given CS-US pairings, its NM response could not be recorded.

(Manuscript received April 5, 1999; revision accepted for publication September 6, 1999.) 